\title{
EXCURSIONES ETNOGRÁFICAS ENTRE LOS PESCADORES DE BALLENAS DE TUMBES Y LA ISLA SANTA MARÍA, CHILE, A COMIENZOS DEL SIGLO XX
}

\author{
Ethnographic excursions between whalers of Tumbes and Santa Maria \\ Island, Chile, in the early twentieth century
}

DANIEL QUIROZ*

Fecha de recepción: 27 de noviembre de 2015-Fecha de aprobación: 9 de mayo de 2016

\section{Resumen}

La caza costera tradicional de ballenas o "pesca de ballenas" se inicia en la zona de Talcahuano en la primera mitad del siglo XIX y luego se extiende hacia el sur de Chile, llegando hasta la Isla Grande de Chiloé. En este trabajo nos interesa escribir una etnografía de la caza costera en Tumbes e isla Santa María, denominada en la literatura de la época "pesca de ballenas". Los datos sobre estas operaciones provienen de una serie de informes escritos a comienzos del siglo XX, complementados con datos provenientes de revisiones documentales administrativas, de búsquedas en diarios locales y de conversaciones con personas que conocieron el oficio de primera mano. La integración de estos datos permite escribir un relato plausible sobre la caza de ballenas en el centro sur de Chile en los comienzos del siglo XX, considerando que se trata de "un evento del pasado".

Palabras clave: caza costera tradicional de ballenas, etnografía histórica, siglo XIX, Tumbes, isla Santa María.

\section{Abstract}

The traditional shore whaling or "whale fishing" began in the area of Talcahuano in the first half of the nineteenth century and then spread to the south of Chile, to Chiloe Island. In this paper we develop a historical ethnography of shore whaling in Tumbes and Santa María Island, named in the literature of the time as "whale fishing". Data on these operations are coming from a series of reports written in the early twentieth century, supplemented with information from interviews with people who knew firsthand the world of whalers. The integration of these data will allow us to write a narrative of whaling in south central Chile in the nineteenth century.

Keywords: traditional shore whaling, historical ethnography, nineteenth century, Tumbes, Santa Maria Island.

\footnotetext{
* Antropólogo Social, Universidad de Chile; Magister en Arqueología, Universidad de Chile; Doctor en Historia, Universidad de Chile (2014). Director del Centro de Documentación de Bienes Patrimoniales de la Dirección de Bibliotecas, Archivos y Museos. Académico del Departamento de Antropología de la Universidad de Chile. Correo-e: danielquiroz54@gmail.com
} 


\section{Apertura $^{1}$}

En 1789 la fragata británica Amelie captura el primer cachalote frente a las costas chilenas, iniciándose un largo período de caza de cetáceos, que se extenderá por casi doscientos años (1789-1983). La presencia de buques balleneros de diversas nacionalidades aumenta considerablemente pasando en 1810 "a ser una incómoda rutina en las costas de Chile" (Pereira Salas, 1971: 69). En 1834 se resalta:

\footnotetext{
"el significativo número de balleneros que recalan en el puerto de Talcahuano, procedentes de sus lugares de pesca, con el objeto de refrescar sus gentes y víveres. Todos manifiestan transportar barriles de aceite de ballena. La tripulación por barco oscila entre veinte y treinta y dos hombres, alcanzando al año a unos mil quinientos marineros de habla inglesa y francesa que pasan por Talcahuano y Concepción"2.
}

La presencia extranjera en las costas chilenas genera diversos proyectos balleneros que siguen el modelo de la caza pelágica yanqui (Reeves \& Smith 2006; Cartes, 2009) e involucran capitales y tripulaciones chilenas (Quiroz, 2015b). Entre 1860 y 1880 la participación chilena aumenta en forma significativa, llegando a conformar una flota de diecinueve buques involucrados en la caza de la ballena desde Talcahuano, Valparaíso y Caldera. Recorrían las costas de Chile, Perú, Ecuador (islas Galápagos incluidas) y Panamá en busca de cachalotes y ballenas jorobadas en viajes que duraban cerca de diez meses (Op.cit.: 2-6). Desde Talcahuano salieron también algunas expediciones al sur para cazar ballenas en los mares antárticos (Sandoval, 1987). El modelo de caza pelágica se mantiene, disminuido pero vigente hasta 1922, cuando el barco James Arnold realiza su último viaje, "con un capitán náutico, otro de pesca, dos o tres pilotos, y veinte a veinticinco hombres", por encargo de Jose Maritano, comerciante de Talcahuano que había adquirido todos los bienes de la sociedad Toro \& Martínez, sucesora de Mathieu \& Brañas (Sandoval, 1987: 235).

La influencia yanqui se sentirá también en el desarrollo de operaciones balleneras costeras en pequeña escala, que hemos denominado "caza tradicional de ballenas" (Quiroz, 2012), que utilizaban botes abiertos y arpones de mano y procesaban sus carcasas en instalaciones costeras bastante precarias, como las de José Olivares, en Caleta Tumbes, Talcahuano (Fernández, 1966) y Juan Macaya en Puerto Norte, isla Santa María (Hernández, 1998). No disponemos de datos muy precisos sobre el inicio de estas operaciones en las costas de Chile, aunque algunos textos indican que José Olivares fue el "fundador de esta industria" en Tumbes, Talcahuano, donde habría estado cazando ballenas desde 1840 y su nombre "se conserva rodeado de una cierta legendaria aureola, que el tiempo agranda y ennoblece" (Dublé Urrutia, 1905; cf. Fernández, 1964; Salvo, 2000).

Usamos indistintamente los términos pesca y/o caza de ballenas reconociendo que el nombre técnico debiera ser caza de ballenas, pues la ballena, evidentemente, no es un pez. Sin embargo, en la literatura en castellano, durante todo el siglo XIX se usa el término "pesca de ballenas" para referirse tanto a la caza pelágica como a la costera, bajo el modelo yanqui.

Desde Talcahuano, la caza tradicional de ballenas se disemina primero por todo el golfo de Arauco, Lebu, isla Mocha, y llega en las postrimerías del siglo XIX, hasta el río Maullín y la Isla Grande de Chiloé (Quiroz, 2012). Proba- 
blemente la primera década del siglo XX sea el momento de mayor desarrollo de la caza costera en el litoral chileno. Desde 1920 la caza tradicional de ballenas comienza paulatinamente a declinar, hasta desaparecer por completo hacia $1950^{3}$. Su decaimiento se debe, al menos parcialmente, a la formación de empresas balleneras modernas en la primera década del siglo XX, tanto en Punta Arenas (Martinic, 2004) como en Valdivia (Quiroz, 2010).

\section{“No estar ahí”}

La captura de ballenas en Chile, es un "evento del pasado", por lo que su estudio requiere el uso de herramientas metodológicas adecuadas, distintas a las tradicionales de la etnografía. El término "etnografía retrospectiva" sirve para nombrar un enfoque que involucra el uso integrado de diversos tipos de fuentes: recuerdos de personas que pudieron observar directamente la experiencia ballenera o les hablaron de ella; documentos administrativos, científicos y literarios, noticias y entrevistas de prensa; visitas a los lugares donde la caza de ballenas se produjo y relevamiento de sus testimonios y huellas materiales (Quiroz, 2014, 2015). El concepto ha sido usado de diversas maneras por antropólogos e historiadores, reflejando su naturaleza algo ambigua o, al menos, polisémica (Gonçalvez, 2009; Driessen, 2013; Bezerra, 2015).

La etnografía retrospectiva es una herramienta que permite estudiar "el pasado de la misma manera como un antropólogo aborda una sociedad exótica" (Thomas, 2009: 2), permite analizar un modo de vida del ayer como si fuera contemporáneo, utilizando "los mejores equivalentes históricos de las observacio- nes de los etnógrafos", para que ese modo de vida reconstituido sirva "como contexto para una explicación de la acción colectiva" (Tilly, 1978: 210).

La antropóloga sueca Rebecka Lennartsson, subraya una sensación de extravío, "como si no tuviera ni un mapa ni una brújula", cuando pretende estudiar el comercio sexual en el Estocolmo del siglo XVIII y siente que las herramientas tradicionales de la antropología no se lo permiten. Señala que si "la etnografía es tanto el método como una forma de expresión de nuestra disciplina, ¿cómo puedo aplicarla en una ciudad que ya no existe?". En otras palabras, "¿puede la etnografía ser usada para describir y comprender un mundo perdido?" (Lennartsson, 2011: 107). Planteado de otra manera, ¿en qué momento y en qué términos el "estar ahí" puede ser reemplazado por el "no estar ahí"? Son las preguntas que nos hacemos cuando tratamos de describir y comprender la pesca de ballenas en las costas del centro sur de Chile. Estos viajes al pasado son pensados como verdaderas "excursiones etnográficas" (Op.cit.: 108).

Otro ejemplo interesante es el trabajo de la antropóloga brasileña Renata de Sá Gonçalves. Habla de un "viaje" al Rio de Janeiro de finales del siglo XIX y que, con la ayuda de las voces de periodistas y cronistas, a veces desde dentro otras desde fuera, pudo narrar los dramas desarrollados en el "carnaval dos ranchos", las antiguas escuelas de samba (2007). Para recorrer ese camino, señala, "me dejé llevar [...] por diarios, revistas y libros, de manera de construir una 'etnografía retrospectiva' de su proceso de estructuración, consolidación y finalización" (2008:7), proponiendo "una lectura etnográfica del material histórico sobre los 'ranchos carnavalescos', con un foco en los cronistas del diario considerado 
como el más 'popular, de la época, el Jornal do Brasil' (2009:76). Estos cronistas son "comentadores e intérpretes privilegiados del carnaval carioca", pues no solo eran "críticos sino también participantes extremadamente activos en el proceso de formación y en la consolidación de esta forma carnavalesca" (Op.cit.:77).

La información de base para conocer y relatar etnográficamente la "pesca de ballenas" aparece en cuatro textos, de distinta extensión y profundidad, publicados entre los años 1902 y 1907. El primero, escrito por Alejandro Cañas Pinochet ${ }^{4}$, es un trabajo breve que nos habla de la pesca de ballenas en Isla Mocha y fue publicado en las Actas de la Sociedad Científica de Chile (1902: 68-69, 72). El segundo, de Diego Dublé Urrutia ${ }^{5}$ describe las operaciones balleneras en Tumbes, Talcahuano y fue publicado por entregas en el diario El Sur de Concepción (Dublé Urrutia, 1905a, 1905b). El tercero, de Luis Castillo ${ }^{6}$ se refiere a la caza de ballenas en la isla Santa María, lugar que había visitado en el invierno de 1905, y fue publicado en el Boletín de la Sociedad de Fomento Fabril (CastiIlo, 1906). El cuarto, escrito también por Luis Castillo, entrega antecedentes sobre "el estado en el que se encuentra la industria de la caza de ballena" al regreso de un viaje realizado en 1906 a las costas de Llanquihue y Chiloé y fue publicado en los Anales Agronómicos (Castillo, 1907). Los textos se refieren a la pesca de ballenas en Tumbes, isla Santa María, isla Mocha y en las "provincias de Llanquihue y Chiloé". Como una manera de "nombrar" ese amplio territorio costero que recorrieron los pescadores de ballenas hemos usado el término "centro-sur de Chile".

La información de estos textos fue complementada con datos administrativos oficiales, como memorias, informes y cartas, tanto impresas como inéditas. Buscamos también en periódicos locales noticias sobre cualquier suceso, cotidiano y extraordinario, relacionado con la pesca de ballenas. Tuvimos acceso también a diversos testimonios de personas que conocieron las operaciones balleneras, "tanto de vista como de oído" y los hemos usado discretamente para elaborar este relato.

En términos generales, los datos recolectados permiten abordar la pesca de ballenas de un modo fragmentario. La primera pregunta que debemos formularnos es ¿qué es la pesca de ballenas? Una respuesta simple permite definirla como la "matanza intencional de grandes cetáceos para obtener productos económicamente útiles" (Reeves \& Smith, 2006: 82). Se usa el término "operación ballenera" como un concepto que permite integrar la información fragmentaria en una configuración específica de significados asociados a las respuestas de un conjunto de preguntas: ¿quién la desarrolla?, ¿qué especies se capturan?, ¿dónde se efectúa?, ¿por qué se las caza?, ¿cuándo ocurre? y ¿cómo se realiza? El término "operación ballenera", se refiere no solo a las formas de capturar los cetáceos, la "matanza", sino también al procesamiento de sus carcasas, con el fin de obtener los productos que luego serán consumidos y/o comercializados (Reeves \& Smith, 2006: 83-84). La información recogida debe servir para poder contestar, de la mejor manera posible, las preguntas planteadas.

Nos interesa reconstruir el proceso de expansión de la actividad ballenera en las costas del centro sur de Chile. También definir quiénes la practicaron, qué especies capturaron, dónde y en qué época lo hicieron, cómo se pescaban y procesaban las ballenas, el equipamiento y 
las herramientas utilizadas, los productos obtenidos, su comercialización y el reparto de las utilidades. También es importante estudiar las transformaciones que experimentó la pesca de ballenas en el tiempo, el uso de lanchas y luego vapores para el remolque de las chalupas y las ballenas, la construcción de instalaciones más adecuadas para el procesamiento de las ballenas, la formación de sociedades comerciales.
El relato que presentamos a continuación es una representación (graphein) de una actividad que fue relevante para muchas personas durante más de un siglo, incluso aún sigue siéndolo en la memoria de sus descendientes. La pesca de ballenas sirvió, además, para identificar una comunidad (ethnos) o, al menos, a los individuos que la practicaron: Tumbes, los Olivares, la Santa María, los Macaya.

Foto 1: Cortando la capa de grasa de una ballena capturada desde caleta Tumbes, c. 1940

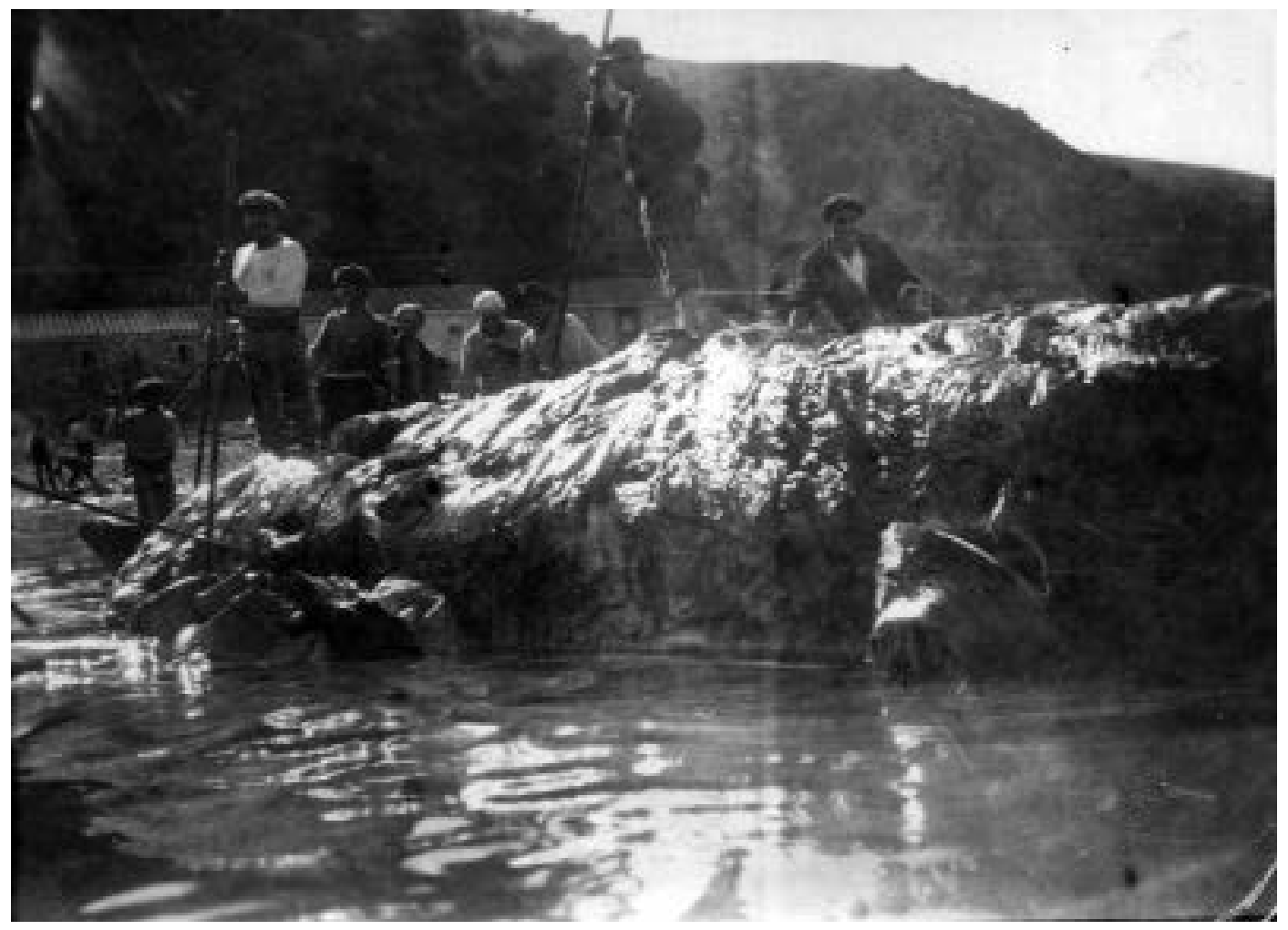

(Foto gentileza de Luis Salvo) 


\section{Historias}

La caza costera de ballenas se inicia en la bahía de Concepción en la década de 18307. Sin embargo, las primeras referencias oficiales sobre la existencia de pescadores costeros de ballenas las encontramos en un informe escrito en 1854 por el Intendente de Concepción, basado en los datos que le entregara Juan Guillermos, en esa fecha Gobernador Marítimo de Talcahuano. Manifiesta que en 1853 "once chalupas hacen la pesca de la ballena, cruzando a las inmediaciones de las costas", agregando que son 66 los hombres "ocupados

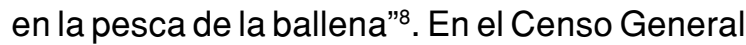
de Población de la República de Chile de 1854 aparecen registrados en Tumbes, San Vicente y Talcahuano 30 balleneros, 28 chilenos y dos extranjeros ${ }^{9}$. La información se incrementa con la llegada en 1857 del capitán de corbeta Carlos Pozzi al cargo de Gobernador Marítimo de Concepción, quién siempre se mostró muy interesado en la difusión y promoción de la industria ballenera. Indica que hacia 1860, hay en el puerto de Talcahuano entre 10 y 12 chalupas balleneras dedicadas a cazar ballenas entre la zona comprendida entre Tomé y la isla Santa María. Estas chalupas se ocupan no solo en la caza de ballenas sino también en la caza de lobos marinos y la pesca de corvinas $^{10}$. Son pescadores y una de sus presas son las ballenas. Pozzi señala "que la pesca de ballenas en esta costa generalmente tiene lugar desde abril hasta noviembre, la pesca de lobos desde enero hasta abril, la de corvinas en octubre hasta febrero inclusive" y resalta que "esta clase de industria es mui benéfica para formar hombres arrojados i acostumbrados a los peligros del mar"11.
Los pescadores de ballenas comenzarán a ocupar paulatinamente todo el litoral del centro sur de Chile en la segunda mitad del siglo XIX. En marzo de 1862 los balleneros de Talcahuano instalan una faena en la desembocadura del río Lebu, a cargo de José Morán (Pizarro, 1994: 114). Lebu será el extremo meridional de una extensa zona de captura para los pescadores de Talcahuano. La autorización otorgada en 1869 a José Olivares, de Tumbes, para "salir a la pesca de ballenas en embarcaciones menores", delimitaba claramente un territorio de pesca en la segunda mitad del siglo $\mathrm{XIX}$, que estaba comprendido por "la isla Santa María, costa de Arauco i Lebu"12.

¿Había en Lebu embarcaciones involucradas en la pesca de ballenas o bien la actividad la desarrollaban solamente pescadores de Tumbes? La memoria del Subdelegado Marítimo de Lebu de 1868 es clara: "No las hai [embarcaciones menores para la pesca de ballenas] y el poco aceite beneficiado en esta costa proviene de la casualidad"13. Esta afirmación se ve reflejada en una noticia donde se indica que el 27 de julio de 1868 han salido del puerto de Lebu, rumbo a Talcahuano, cuatro chalupas balleneras, con 24 tripulantes, al mando del capitán T. Parra ${ }^{14}$. La primera referencia clara de la presencia de embarcaciones balleneras registradas en el puerto de Lebu se encuentra recién en la Memoria de la Gobernación Marítima de Concepción de 1876, donde se indica que "las nueve chalupas están ocupadas en pescar ballenas i otros pescados i en remolcar buques i lanchas; también se ocupan en sacar los pasajeros de los vapores"15.

En las postrimerías del siglo XIX los pescadores de ballenas llegan a Valdivia. En la Memoria del Ministerio de Marina correspondiente a 1897 
se señala la existencia en el puerto de Corral, cerca de Valdivia, de cuatro chalupas "para la pesca de la ballena"16 (Ramos, 1897: 839). La pesca de ballenas, con chalupas y arpón de mano, se mantiene en la zona durante bastante tiempo y era recordada por nuestros entrevistados en la zona de Corral:

“(..) mi papá cazó ballenas con chalupa, con arpón a mano, las chalupas trabajaban con remolcadores, que llevaban las ballenas a la playa o si no la misma chalupa la traía a la orilla [...] las chalupas tenían también su mástil y velas; el remolcador era el San Carlos, ese iba recogiendo las ballenas"17.

El remolcador San Carlos, que llegó a Chile en 1910, pertenecía al establecimiento ballenero de San Carlos de Corral de la Sociedad Ballenera de Corral, donde se practicaba la caza moderna de ballenas con vapores balleneros, pero, en forma paralela, continuaron cazando con chalupas y arpón de mano. Estos pescadores entregaban sus ballenas o el aceite a la Sociedad Ballenera de Corral para su procesamiento (Quiroz, 2013).

La pesca de ballenas continuó expandiéndose hacia el sur de la mano de pescadores que venían de Talcahuano, Lebu y Valdivia. En 1903 se asegura "que los balleneros llegados últimamente de Valdivia han pescado hoy dos ballenas de gran tamaño cerca de la boca de Maullín"18, las que han procesado en sus instalaciones de Punta Chocoy, Carelmapu ${ }^{19}$. Un mes más tarde se indica que estos mismos balleneros embarcaron en el vapor Ecuador a Lebu "una gran cantidad de aceite y barbas de ballena, por valor de doce mil pesos, y se calcula que hasta la fecha hayan sacado una utilidad de catorce mil o más pesos"20. En 1905 se informa que es "increíble el desarrollo que ha tomado la pesca de la ballena" en la zona de Maullín:
“(...) en los parajes cercanos a los ríos i en la playa de Quillagua se han establecido en el corto transcurso de un año 7 compañías, aparte de otra establecida en la isla Amortajado [...] cada compañía cuenta con tres $\mathrm{i}$ cuatro chalupas bien armadas i que con gran empeño se entregan a la caza"21.

En la Isla Amortajado se instaló una planta ballenera, "donde se faenaba, se derretía el aceite y después era enviado a Valdivia para la elaboración de velas". Entre estos balleneros estaba Esteban Sanhueza, que "era oriundo de caleta Tumbes y fue uno de los impulsores de la ballena con la compañía Soto Pérez, quiénes se encargaban de faenar la ballena que se trabajaba en Maullín y Carelmapu" (Chambeaux et al.: 2009: 19)22. En 1908 se comenta sobre la favorable:

"pesca de ballenas, que para este pueblo es una gran fuente de riqueza [...]; la empresa de don Juan de Dios Díaz logró pescar una valiosa ballena [...] es uno de los [ejemplares] más grandes cazados en la última semana [...]. Es el tercero pescado en los últimos 15 días. No puede ser más halagador, pues, el resultado que han obtenido hasta el presente las empresas balleneras establecidas en esta villa, pues solo en barbas se evalúan en nueve mil pesos cada una"23.

Unos días después "comunican de Maullín que la pesca de ballenas ha alcanzado un auge asombroso i halagador para los que a la pesca de estos cetáceos se dedican. Una sola empresa prestadora ha obtenido enormes ejemplares en el corto espacio de dos días. ¡Bien por Maullín!”24.

Los resultados obtenidos en Maullín despertaron "mucho entusiasmo por la pesca de ballenas" en otros lugares y Teodoro Kamman, comerciante ancuditano, trae en 1903 de Lebu, en el vapor Ecuador, "dos chalupas balleneras, 
tripuladas por 14 hombres". La prensa augura que "ojalá esta nueva industria sea una verdadera fuente de riqueza para los empresarios que la explotan"25. Después "de algún tiempo de esperar", alcanzaron "a trancar uno de esos bichos que dado sus proporciones le dejará una buena utilidad"26.

Sixto Venegas, de Pumillahue, Chiloé, relata que su abuelo, Aurelio Venegas, ballenero en Corral, se trasladó a trabajar a Puñihuil. Es así como seis o siete botes pequeños, de 607 metros de eslora, salían desde la caleta a cazar ballenas cerca de la Isla Metalqui. La ballena era lanceada con arpones hasta desangrarla, luego los botes eran amarrados entre sí, para hacer peso y de esta manera cansar el animal y acelerar su desangre. Una vez muerto, el animal era remolcado a Puñihuil y en esta playa se destazaba y se extraía su aceite. Sixto Venegas cree que los balleneros eran en su mayoría de Valdivia-Corral y unos pocos de Chiloé, aseverando que en el sector de Pumillahue ahora "ninguno tiene experiencia de nada"27.

\section{Excursiones}

Dublé Urrutia tuvo en Tumbes un "informante clave", el capitán ballenero Rodrigo Olivares, "mi trancador amigo, quién es quién me da hoy tantos e interesantes datos (1905a: 4). Luis Castillo no pudo "tomar parte en las faenas de la caza" en isla Santa María por lo que se limitó a recorrerla "en casi todo su contorno, ocupándome en recoger los datos que estimé necesarios para ilustrar este informe" e hizo "equipar una chalupa ballenera con todos los útiles empleados en la caza, procurando que los tripulantes se desempeñaran en sus respectivos cometidos" (Castillo, 1906: 3). Cañas Pinochet obtuvo sus datos mediante conversaciones con pescadores de isla Mocha (1902: 68-69, 72). La información relativa a la pesca de ballenas en Llanquihue y Chiloé fue obtenida tras una visita que Castillo hizo a la zona para elaborar un informe sobre el estado de la pesca de la ballena (1907: 158).

\section{1}

La caza costera de ballenas a comienzos del siglo XX era practicada por familias de pescadores, "que hacen su principal oficio de esta famosa caza" (Dublé Urrutia, 1905a: 4). José Olivares, "fundador de esta industria en Tumbes" y cuyo nombre "se conserva rodeado de una cierta legendaria aureola, que el tiempo agranda y ennoblece" (Dublé Urrutia, 1905a: 4), era hijo de españoles y habría nacido en Constitución, Chile (Salvo, 2000: 64). En Tumbes, además de los Olivares estaban "los Bécares" (Dublé Urrutia 1905a: 4). Castillo no menciona en su trabajo los nombres de los cazadores de ballenas en la Isla Santa María con los que se entrevistó en 1905 pero resalta "el apego que tienen a esta industria los habitantes de la isla, a pesar de los pocos medios de que pueden disponer i de los muchos peligros a los que se exponen hoy día en cada minuto de labor" (Castillo, 1906: 6). Cañas Pinochet indica que en Isla Mocha "el interés se halla difundido entre muchos aunque no todos poseen los elementos de pesca ni las cualidades de valor, previsión, agilidad i serenidad que se requiere en estas riesgosas empresas" (1902: 68), sobre todo debido a que una sola ballena "suele dar en pocos días de trabajo, lo que no se obtiene en meses de ocupaciones de labores de las tierras" (Op.cit.: 69). Entre los inquilinos de la Hacienda de la Mocha "hay algunos arrojados balleneros 
que por placer, más que por utilidad pecuniaria, pescan todos los años algunas ballenas" (Ídem: 72), agregando que "un pescador de la isla, tal vez el más arrojado i diestro de todos, Pedro Ríos, [...] ha fisgado i 'amarrado' diecinueve ballenas" (Ídem: 69). Luis Castillo señala que "más de veinte empresas balleneras en las dos provincias de Llanquihue i Chiloé" se ocupan de la caza de la ballena franca, siendo en muchos lugares una de "las tareas preferentes de la población" (Castillo, 1907:162).

Los pescadores reconocen seis especies de ballenas, pero cazan regularmente solo dos de ellas, "la denominada vulgarmente ambaqui (del inglés humpback)" y "la conocida con el nombre de reituel, también del inglés right whale". La caza se haría extensiva ocasionalmente a la orca, cetáceo "conocido con el nombre de ballena quila, que es killer entre los norteamericanos" (Castillo, 1906: 496; Dublé Urrutia, 1905a: 4). Los pescadores reconocerían también el espamuel o cachalote (sperm whale), la alfaguara (blue whale), y la finbaqui (finback), pero no son capturadas pues no poseen las herramientas necesarias para hacerlo. En Tumbes se captura principalmente la reituel y la ambaque (Dublé Urrutia, 1905a: 4). En la Santa María, "la ambaqui, ballena cosmopolita, es la que más se caza en la isla" (Castillo, 1906: 495), pero también la reituel "la de mayor valor por sus barbas y su aceite" (Op.cit.: 496). En las costas de Llanquihue y Chiloé la captura comprende "a un solo cetáceo de nuestros mares [... la] denominada vulgarmente reituel' (Castillo, 1907:162).

La cacería se realizaba durante los meses de marzo a noviembre, época en la que dichas especies se trasladaban a través de las costas chilenas y mucho más allá, desde sus lugares de alimentación a los de procreación.
Los balleneros de Tumbes cazaban en un área bastante extensa:

"(...) los riscos de Santa María y de la Mocha, las caletas de más al norte y todas las arenas de nuestra costa, hasta Ancud, conservan todavía las enormes quijadas, vértebras y costillas de los monstruos vencidos, cuerpo a cuerpo, por Olivares (...) en la segunda mitad del siglo pasado" (Dublé Urrutia, 1905a: 4).

Los balleneros de Isla Santa María cazaban en los alrededores de la isla, hasta 3 millas de la costa (Castillo, 1906: 499). Lo mismo ocurría con los balleneros de Isla Mocha (Cañas Pinochet, 1902: 72).

Cuando los pescadores de Tumbes viajaban lejos de sus lugares de residencia se instalaban por un período de tiempo en alguna caleta o playa apropiada. Así lo hicieron los Olivares en Lebu, en Maullín y en otros lugares de la costa chilena.

Los pescadores de Maullín recorrían diversos puntos de la costa para pescar ballenas. Se cuenta que el conocido industrial "don José 2 Pérez en un corto lapso de tiempo ha pescado cuatro hermosísimas ballenas en los siguientes lugares: una en San Pedro, dos en los mares de Cucao y otra en la costa de Maullín". La pesca se había iniciado recién "el 5 de septiembre, eso sí, favorecido por el buen tiempo que ha reinado en todo este mes" Se indica que: "parece que las ballenas cogidas son de una buena clase y le rendirán una buena cantidad. Últimamente el señor Pérez se ha dirigido a los mares del sur con todos los elementos necesarios para perseguir la pesca de cetáceos. Le deseamos buena suerte" 28 . Los pescadores, con el fin de atraer i matar a la madre, disparan i matan primero a la cría. De las ballenas solo aprovechaban las barbas, abandonando en el mar, el 
cuerpo i el aceite". El corresponsal manifiesta una temprana preocupación por el efecto de este tipo de cacería sobre las poblaciones de ballenas $^{29}$.

\section{2}

El avistamiento de las ballenas en Tumbes es más bien fortuito: "algún chiquillo ocioso o alguna mujer que andaba en la cosecha de papas del fundo 'de allá arriba' llegan de carrera anunciando que han visto ballena" (Dublé Urrutia, 1905a: 4). En la isla Santa María, cuando el tiempo lo permite,

\footnotetext{
"(...) siempre hay un hombre apostado en una de las cumbres de la isla, de las más inmediatas a la playa [...], explorando el horizonte con ayuda de un anteojo, $\mathrm{i}$ cuando ve aproximarse un ejemplar, anuncia la presencia del monstruo a sus compañeros de embarcación, procurando hacerlo con el mayor sigilo para que su descubrimiento no sea aprovechado por los demás colegas de labores, que como él, están en acecho de su presa" (Castillo 1906: 497-498).
}

Cuando se divisa una ballena, los preparativos para la captura se aceleran, se aparejan y se lanzan al agua las chalupas: "en la proa el trancador, o matador, en la popa el piloto (generalmente el dueño de la embarcación) i en los bancos cinco bogadores, dispuestos a remar sin descanso, en silencio i sin miedo, 10, 12 i hasta 24 horas seguidas". El piloto lleva un catalejo para observar atentamente la ballena "como una mancha relumbrante, arrojando columnas de agua a ratos" (Dublé Urrutia, 1905a: 4).

Se inicia la persecución. Una vez acorralada la ballena, con la chalupa a su lado, el piloto da la orden de 'trancar' y 'el 'trancador' se pone de pie en la proa i cogiendo el arpón [...] lo lanza como una flecha sobre alguno de los puntos orgánicos de la ballena, de modo de traspasarle el corazón o alguna otra parte igualmente delicada" (Dublé Urrutia, 1905b: 1). Se sabe "que la parte más vulnerable de las ballenas es el costado, más o menos por la mitad del cuerpo. Si el golpe de arpón se lanza cerca de la cola, se pierde seguramente porque ahí no entra i se corre el riesgo de perderlo todo por el recio golpe con que la ballena tumba a la embarcación con la sacudida de muerte que da con la cola para defenderse del arpón". Si el arponero tiene éxito, se dice que la ballena ha sido 'fijada'. Al 'fijar' la ballena, uno de los bogadores, que ha dejado de remar, para controlar su calentamiento por fricción "moja la línea, variando en alguna cierta cantidad de agua, que luego se filtra por los numerosos agujeros practicados en el fondo" (Castillo, 1906: 498). Herida la ballena huye, "arrastrando hasta ochenta i cien brazas el cabo línea que va unido al arpón" (Dublé Urrutia, 1905b: 1).

En la chalupa los bogadores dejan entonces los remos y todos "se cogen al cabo línea que jamás se amarra al barco, largando i largando cabo hasta que se siente que la ballena deja de bajar, comienza a huir en dirección horizontal o bien vuelve a salir sobre las olas" (Op.cit.:1). En ese momento los tripulantes "proceden a recoger la línea con prontitud, hasta notar en ella una marca que les revela la proximidad del cetáceo, que busca la superficie para poder respirar i que se encuentra desde este momento a tiro de lanza". Para maniobrar con la lanza, se requiere que el timonel, ayudado del resto de la tripulación coloque el bote "de manera que pueda desde ahí lanzar el animal en el mismo costado donde fue fijado por el arpón. Se da uno i hasta tres lanzazos, o más bien dicho, le da los que alcanza, recogiendo 
el arma con presteza, inmediatamente que se hace uso de ella" (Castillo, 1906: 498). Los autores indican que "este es el momento en que el animal pelea de veras" (Dublé Urrutia, 1905b:1). La ballena, entonces, sintiéndose nuevamente herida, ya de muerte, "se sumerge con lentitud, inclinándose comúnmente de un lado a otro, agoniza tiñendo el agua con su sangre, hasta que luego queda completamente inanimada" (Castillo, 1906: 498). Finalmente, la ballena "se vuelve de espaldas" y muere, "de resultas del arponazo o de las lanzadas o bien del tiro del bombo lanza [...] pero el bombo lanza -con nobleza marinera digna de respeto- solo es usado en casos extremos por los pescadores de 'lo fino"' (Dublé Urrutia, 1905b: 1).

Los tripulantes de la chalupa, "se acercan [...] para cerrarle la boca, evitando con esto que el animal de llene de agua i haga más costosa la tarea" (Castillo, 1906: 498) y para hacerlo "se le mete un arpón en la boca i se le cose ésta con el cabo línea" (Dublé Urrutia, 1905b: 2). Finalmente "los esforzados bogadores sumergen sus remos i avanzan arrastrando el monstruo lentamente, guiándose a menudo solo por la luz del faro, sin divisar la playa de la isla" (Castillo, 1906: 498). Indudablemente esta tarea es de mucho esfuerzo. Si consideramos que las ballenas se 'fijan' a unas: "tres millas de distancia de la costa de la isla Santa María, dicha distancia se aumenta por el espacio que recorre el cetáceo en su huida i todo esto corresponde al trayecto que se tiene que remolcar el animal para vararlo en la playa" (Op.cit.: 499). Esta operación es muy fatigosa y, en el caso de los pescadores de Tumbes, "suele durar hasta tres i cuatro días, según la distancia de Tumbes a que se verificó la caza. Una legua se anda, a veces, en cuatro o cinco horas" (Dublé Urrutia, 1905b: 2). En la isla Santa María se utilizan bueyes para arrastrar la ballena hasta la orilla (Castillo, 1906: 499).

Una vez que la ballena llega a la playa, "entre el general entusiasmo de la jente" (Dublé Urrutia, 1905b: 2), se procede a beneficiarla. Para hacerlo "se corta el animal en tres partes i haciendo tres trozos de la cabeza, el cuerpo i la cola" (Op.cit.:2). En la playa se destrozan estas partes con 'espeles', cuchillos triangulares especiales para el tocino (Dublé Urrutia, 1905b: 2). Los trozos o 'tajadas' de tocino son de una vara de largo (Castillo, 1906: 498). Este tocino "se hierve en fondos grandes de hierro i así se saca el aceite" (Dublé Urrutia, 1905b: 2). En la isla Santa María, la administración de la hacienda

"proporciona dos fondos buenos de 150 galones cada uno, i algunos más que se encuentran en mal estado, de menor capacidad; ocho enfriaderas de aceite de tamaño variable i entre las que la mayor puede contener 800 galones i la menor solo 300" (Castillo, 1906: 499).

La utilización de las carcasas no era del todo eficiente: en la isla Santa María "el cadáver queda botado en la playa después de sacarle la grasa, i no toda, aprovechándose de su carne las gaviotas, jotes, tiuques i pájaros carneros; además, en todo tiempo, se deja sentir un mal olor aún a distancias considerables, i principalmente en el verano se respira un ambiente de una fetidez pútrida insoportable" (Op.cit.: 499). En Tumbes ocurría algo muy parecido. 
El tamaño más común de las chalupas

El equipamiento de la caza tradicional de ballenas está formado por aquellos implementos usados tanto para conducir a los balleneros lo suficientemente cerca de la ballena (embarcaciones), como los diseñados para capturar, matar y recuperar la presa y aquellos para transformar sus carcasas en productos comercializables, tales como aceite, barbas, carne y huesos (Pearson, 1983: 41). Según los textos consultados el equipamiento en este caso estaría constituido por las "embarcaciones", el "armamento", las "herramientas" y los "recipientes". La embarcación recibe el nombre de chalupa; el armamento está formado por varios arpones, lanzas y, en ocasiones, un fusil ballenero; las herramientas corresponden a principalmente a cuchillos (espeles) para descuartizar la ballena; los recipientes son "fondos" para cocinar el tocino y "enfriaderas" para almacenar temporalmente el aceite. Seguramente se usaron otras herramientas pero no hay datos sobre ellas.

Los balleneros poseen "magníficas embarcaciones, livianísimas, de construcción yanqui" (Dublé Urrutia, 1905a: 4). Estos botes balleneros, o whaleboat, son abiertos, "angostos, ligeros, construidos de aproximadamente unos 25 pies de longitud, apuntados en ambos extremos, con sus lados elegantemente curvados y levantados hacia proa y popa" (Olmsted, 1841: 19). Los whaleboat están "adaptados a los movimientos veloces y seguros en medio de los temporales del océano" (Op.cit.: 19). Estos botes derivan seguramente de la txalupa vasca del siglo XVI: "una embarcación menor sin cubierta y con remos y vela (s), usada tanto para la pesca [...] como para la caza de ballenas [...] siendo tripulada en estas faenas balleneras normalmente por entre seis y ocho personas" (Barkham Huxley, 1998: 206). usadas en Chile corresponde a botes de unos $8,5 \mathrm{~m}$ de eslora, por $2,5 \mathrm{~m}$ de manga y $0,7 \mathrm{~m}$ de puntal e iba tripulada casi siempre por cinco o seis hombres:

"El dueño de la embarcación es a la vez piloto, encargado del manejo del timón i la dirección de la maniobra. Los cuatro que van más adelante, es decir en sentido de popa a proa, i sentados unos detrás de otros, son los bogadores; por fin, el sexto, situado siempre a proa, va de pié; es el trancador, i de él dependen los primeros resultados. Como por regla general es un marino avezado, curtido por las intemperies del clima, va ligeramente vestido, explorando el soplo del animal que se acerca rápidamente i con el arpón empuñado dispuesto a fijarlo en el animal con certero golpe, aguardando por segundos el momento oportuno para desempeñarse en su cometido" (Castillo, 1906: 498).

La información apunta a que las primeras embarcaciones fueron obtenidas de los mismos barcos balleneros extranjeros que recalaban en Talcahuano y que, posteriormente, los modelos fueron copiados por carpinteros de ribera nacionales y reproducidos según las necesidades. Lo mismo debe haber sucedido con las herramientas utilizadas tanto en la caza (arpones, lanzas, líneas, fusiles) como para el procesamiento de las ballenas (cuchillos, ganchos, calderos, barriles, etc.). Para el caso de Tumbes se indica que las embarcaciones se construían en la misma caleta "en base a plantillas de manufactura inglesa o norteamericana que se encargaban, al igual que los implementos que se empleaban en la caza (arpones, lanzas, cabos de manila, etc.) a los veleros balleneros que llegaban hasta nuestras aguas", incluso "algunas embarcaciones eran encargadas a Inglaterra por medio de los veleros" (Fernández, 1964: 38-39) ${ }^{30}$.

Cada chalupa contiene un cierto número de arpones y lanzas. No basta con un solo ejem- 
plar de cada arma. Dublé Urrutia señala que en Tumbes cada chalupa lleva tres arpones y tres lanzas (1905a: 4).

El arpón es "un tubo metálico, macizo en uno de sus extremos i terminado en una pieza de resorte que se abre luego de ser prendida en el animal" (Castillo, 1906: 498), o "terminados en una flecha de hierro que retiene el arma dentro del animal" (Dublé Urrutia, 1905a: 4). Al tubo se le adapta un mango de madera que tiene unos $2 \mathrm{~m}$ de largo y $10 \mathrm{~cm}$ de diámetro (Castillo, 1905: 6). El mango y el tubo metálico van unidos a un cordel (la línea), de longitud variable, que se enrolla "en una tina colocada próxima al bogador de popa" de modo "que podía extenderse con prontitud i sin peligro de que se enredara" (Castillo, 1906: 498) "conservándose el extremo sin amarrarlo a la chalupa, en ningún caso" (Dublé Urrutia, 1905a: 4). En la proa la línea "daba dos vueltas por un tronco de luma colocado sólidamente a manera de un carrete de $30 \mathrm{~cm}$ de alto por 25 de mayor grosor (Castillo, 1906: 498). La línea podía tener unas "200 brazas de largo" (Dublé Urrutia, 1905a: 4) aunque la que Castillo mide en la isla Santa María "tenía 150 brazas y un diámetro de $3 \mathrm{~cm}$ " (Castillo, 1905: 498).

La lanza es "un aparato de las dimensiones del arpón i que tiene, a la manera de este último, su mango en conexión con un cordel bastante largo (Ídem: 498), pero es más delgado que el del arpón, lo "que permite sacarlas de la herida" (Dublé Urrutia, 1905a: 4).

Algunas embarcaciones llevan además "un bombo-lanza, el fusil enorme con cuatro o cinco granadas explosivas, para rematar la ballena, en caso de que no pueda ser herida con las otras armas" (Op.cit.:4). Estos fusiles fueron utilizados en la caza de ballenas, con distinta suerte, desde mediados del siglo XIX. En el bote ballenero, el fusil se llevaba a estribor en "una caja larga cubierta con un trozo de tela, [...y] era disparada desde la proa por el primer oficial, en la misma forma que una escopeta o rifle normal" (Clark, 1887: 253-254). En Tumbes se usaron "carabinas balleneras de manufactura inglesa ${ }^{31}$ que denominaban bombo lanza $\mathrm{a}^{32}$, de un largo de $94 \mathrm{~cm}$, y de un peso de $7,5 \mathrm{~kg}$, que lanzaban arpones de $45 \mathrm{~cm}$ por una pulgada de diámetro, hechos en bronce, que estallaban a los 10 o 15 segundos una vez clavados. Este instrumento permitía aminorar el riesgo de volcamiento de la chalupa por parte de la ballena herida" (Fernández, 1964: 39; cf. Dublé Urrutia, 1905a: 4).

Las referencias en los textos a los implementos usados en el procesamiento de las carcasas son muy breves. Los espeles son cuchillos triangulares usados para cortar el tocino (Dublé Urrutia, 1905b: 2). El tocino se hierve en 'fondos, grandes recipientes de hierro para sacar el aceite (Op.cit.: 2). Las enfriaderas de aceite son de tamaño variable, con capacidades entre 300 y 800 galones (Castillo, 1906: 499).

\section{4}

Los productos obtenidos por este tipo de caza eran el aceite y las barbas de ballena (en algunos casos se aprovechaba la carne que era consumida localmente). Una ballena "mediana" capturada en Tumbes rinde 40 barriles de aceite (es decir, 1.200 galones) y 500 libras de barbas. El galón se aceite se vende a $\$ 0,40$ y la libra de barbas a \$ 0,60 (Dublé Urrutia, 1905b: 2). En la isla Santa María "un buen ejemplar" de ballena franca rinde "3.000 a 4.000 galones de aceite" y "6 a 7 quintales de excelente barba" (CastiIlo, 1906: 496). En Llanquihue y Chiloé, donde 
solamente se caza la raituel o ballena franca, un ejemplar adulto:

“(...) puede proporcionar de 7 a 9 quintales de barbas que sin elaborar o en bruto se vende ya en Ancud como en Maullín a razón de $\$ 900$ el quintal. Puede también llegar a producir, el mismo ejemplar, de cuatro a cinco mil galones de aceite, por valor de otros tantos miles de pesos, bastando para esto freír la grasa con el procedimiento primitivo, insano e imperfecto que todavía se mantiene en uso en el país" (Castillo, 1907: 162).

No disponemos de información sistemática sobre cantidades de ballenas capturadas y producción de aceite y barbas de ballena a través del tiempo. Solamente información fragmentaria. En 1863 José Olivares, de Tumbes, con seis chalupas, captura siete ballenas, que produjeron 6.576 galones de aceite y 2.791 libras de barbas $^{33}$. En 1874 el mismo José Olivares y sus seis chalupas cazaron cuatro ballenas, que produjeron 8.051 galones de aceite y 1.556 libras de barbas $^{34}$. Es interesante señalar que en 1864 se extrajeron en promedio 1.330 galones de aceite por ballena mientras que en 1875 fueron 2.010 galones de aceite por ballena. También podemos comparar la cantidad de libras de barbas obtenidas por ballenas. En 1863 fueron 269 libras de barbas por ballena y en 1875385 libras por ballena ${ }^{35}$. Esto puede significar que se capturaron ballenas con más "gordura" o más "grandes", o bien que se mejoraron los sistemas de procesamiento de las ballenas.

En 1863 los pescadores de la zona de Talcahuano capturaron en total trece ballenas, que produjeron 17.287 galones de aceite y 3.491 libras de barbas, que se vendieron a $\$ 0,65$ el galón de aceite y $\$ 0,25$ la libra de barbas ${ }^{36}$. En 1883 "los botes pescadores de la costa" aportaron "más o menos, 10 mil galones de aceite de ballena"37. En 1919 los balleneros de Tumbes produjeron "6.350 galones de aceite negro, avaluados en $\$ 7.560 " 38$.

Dublé Urrutia señala que los "pescadores libres" de ballenas entregaban "a las compañías mayores el fruto de su industria" (1905a: 4). Estas compañía mayores eran la Sociedad Toro \& Martínez y luego José Maritano, de Talcahuano, y la Compañía Chilena de Balleneros, de Valparaíso. En 1884 se indica que la Compañía Chilena de Balleneros, de Valparaíso tiene "en Talcahuano y Lebu pescadores, con los correspondientes botes y aparejos, listos para la caza de ballenas que aparezcan por dichas latitudes"39. Estas mismas compañías reclutaban a los pescadores de Tumbes "para pilotear sus botes o "trancar" el monstruo", en los viajes que sus veleros hacía a las Galápagos y Panamá (Op.cit.: 4).

En el caso de los cazadores de Isla Mocha, el "aceite y barba lo venden a la Hacienda, la que luego revendía la producción al mismo José Maritano en Talcahuano como también a algunas casas comerciales tanto de Valparaíso como de Santiago" (Cañas Pinochet, 1902: 72).

Los ingresos del beneficio de las ballenas en Tumbes se dividen en dos mitades: "una corresponde de lleno al dueño de los botes en su calidad de dueño" y la otra se reparte entre tripulantes que participan en la cacería. Como en Tumbes la cacería se realiza con cuatro embarcaciones del mismo dueño, la segunda parte "se reparte entre los 4 pilotos, los 20 bogadores y los 4 trancadores de los cuatro botes, i el que dio el aviso de la aparición de la ballena" (Dublé Urrutia, 1905b: 2). El piloto gana como dos hombres, el trancador como un hombre y medio, y cada remero y el avisador como un solo hombre (Op.cit.: 2). Es decir, la segunda parte se divide en 35 partes. En el caso de la 
ballena "mediana" mencionado más arriba, cada una de estas pequeñas partes sería de alrededor de $\$ 50$.

En la Isla Santa María la distribución de los ingresos es algo diferente: pues "la Hacienda cobra por préstamos de estos útiles [fondos y enfriaderas], por la leña i los bueyes que proporciona para fundir el aceite i encallar las ballenas respectivamente, la cuarta parte del valor total de la utilidad" (Castillo, 1906: 499). Los ingresos se dividen primero en ocho partes, dos partes le corresponden a la Hacienda, una al dueño del bote, una al piloto o timonel y otra al trancador. Las tres partes restantes se dividen en novenos, correspondiéndole un noveno adicional al dueño y dos novenos a cada bogador (Op.cit.: 499).

En las "pesquerías" de Llanquihue y Chiloé "el empresario corre con el abastecimiento de víveres para la tripulación formada de seis hombres por cada chalupa, i con todos los cuales se reparte por mitades las utilidades del negocio". El empresario también aporta "las embarcaciones y aparejos de caza, encargándose del sostenimiento del personal cuando no hay trabajo o cuando el mismo personal que caza la ballena, se encuentra absorbido en las tareas de aprovechamiento industrial del cetáceo". Es necesario acotar que "el sostenimiento de las tripulaciones lo hace el empresario a cuenta de lo que a éstas les corresponde percibir después de liquidadas las utilidades del negocio" (Castillo, 1907: 159).

\section{Transformaciones}

Luis Castillo planteaba en 1906 que la única forma de consolidar la actividad ballenera en la isla Santa María era con:
“(...) una empresa ballenera bien instalada en la isla, que pudiera disponer de un vapor remolcador, de un personal competente destinado en parte a la caza de animales con útiles modernos y en parte a la elaboración de sus productos, podría cuando menos obtener diez veces el número de ballenas que se caza actualmente (...) Mi opinión sobre el particular es que debiera dejarse enteramente al criterio privado de los industriales nacionales el fomento de esta clase de tareas" (Castillo, 1906: 6).

La respuesta a los planteamientos de Castillo será la formación de la empresa de Juan Macaya y sus doce hijos, diez hombres y dos mujeres ${ }^{40}$.

Juan Macaya es el ballenero más conocido de Isla Santa María. Había nacido en Lota en 1859 y trasladado a la isla en 1883, donde fue administrador del peñón, contratista de la Armada, pescador, buzo de escafandra y finalmente ballenero (Hernández ,1998: 15-16). Según cuenta Hernández, un historiador local, en 1890 llega a la isla Juan da Silva, portugués, que tenía vastos "conocimientos tecnológicos en la caza y elaboración de los cetáceos" (Op. cit.: 44). La unión entre Juan Macaya y Juan da Silva, la "Sociedad de los Dos Juanes", significará un impulso decisivo para la consolidación de la cacería de ballenas en la isla. Anselmo Macaya, uno de los hijos mayores de Juan Macaya, describe someramente esta relación: "Por circunstancias que ignoro recaló en la isla un portugués aventurero de apellido Da Silva. Había trabajado con los ingleses en la caza de la ballena. Su experiencia en este rubro era notable. Conversó con el abuelo ${ }^{41}$ con el propósito de convencerlo y luego de muchas conversaciones y demostraciones prácticas, se dieron a la tarea de cazar ballenas. Fue a fines del siglo pasado y desde entonces todos los Macaya estamos metidos hasta la tusa en esto". Anselmo agrega además que "el propio 
Da Silva primero y el abuelo después fueron los arponeros" ${ }^{\prime 2}$. No hay certeza respecto del momento preciso en que la denominada "Sociedad de los Dos Juanes" realiza sus primeras cacerías pero en la primera década del siglo XX estaba operativa (Hernández, 1998: 16-17).

En esos años, las ballenas se capturaban con chalupas y arpón de mano. El capitán debía acercar mucho la chalupa a la ballena para tener éxito: "se le arrimaban bien encimita y ahí le tiraban el arpón, y soltaba rápido el cordel para no voltear la chalupa [...] ahí la ballena salía disparada con la embarcación y paraba cuando se cansaba y se hacía el remate"43. Debido a que las embarcaciones eran pequeñas el número de ballenas capturadas no era muy alto:

\section{"(...) con suerte podían traerse una en cada bote no más... si salían en tres botes traían tres ballenas, si es que les iba bien, y volvían a la isla arrastrando, eso significaba un enorme trabajo. Bogaban y bogaban y bogaban, en la noche y en el día. Dicen que dormían y bogaban, y lo hacían"44.}

Si el trabajo de capturar y remolcar la ballena era pesado, también lo era su procesamiento en tierra. Cuando el animal llegaba a tierra "entonces de afuera empezaban a tirarla con líneas, o sea con cordeles, todos íbamos a ayudar, y con dos yuntas de bueyes los tiraban para afuera"45. El animal se descuartizaba en la playa y la grasa era freída en unos latones dispuestos en la misma orilla, proceso en el que se perdía gran parte del aceite ya que mucha de la grasa quedaba en el agua o en la playa sin poder ser usada por los cazadores (Espinoza, 2011: 66).

Una de las primeras innovaciones tecnológicas desarrolladas por los Macaya en la isla Santa María fue el uso de lanchas a motor para el remolque de las ballenas a la playa. Su uso fue bien recibido pues aliviaba el trabajo de los tripulantes y optimizaba el rendimiento de las chalupas, dedicadas ahora solamente a la caza de la ballena. La ballena:

"(...) se cazaba a remo, a puro remo, pero el remolque era en lancha. Yo era chiquitito, tendría mis doce años, cuando conocí la primera ballena que llegó ahí (...), trabajábamos en ir a buscar el espele, con el que cortan el tocino. Entonces le mete un gancho al tocino, lo saca y lo va cortando hasta que queda del porte que usted puede echárselo al hombro (...), lo lleva a los fondos y ahí los echa (...) con eso me ganaba la vida en la isla, ahí me quedé con los Macaya"46.

Las principales dificultades de estos primeros años eran la pérdida del aceite debido al precario procesamiento de las carcasas de las ballenas en el agua y la playa y la larga y trabajosa tarea de remolcar los cetáceos capturados a la costa, a pesar del uso de lanchas a motor.

Con el fin de mejorar la eficiencia, era necesaria una reestructuración del trabajo ballenero, tarea que fue asumida por Don Juan Macaya y sus hijos. En 1932 se constituye la sociedad comercial Compañía Chilena de Pesca y Comercio Juan Macaya Aravena e Hijos y se construye una planta para el procesamiento de la ballena en Puerto Macaya, Isla Santa María (Hernández, 1998: 39-40). La construcción de la planta ballenera de isla Santa María fue una ardua tarea:

"(...) la hicieron a puro pulso, los cabros se levantaban a las tres, cuatro de la mañana, e iban a buscar piedras en saco al otro lado de la isla, con eso armaron la rampa, porque a ese lado del golfo no había piedras, había al otro lado, cuando bajaba la marea aprovechaban y traían las piedras" 47 .

En 1933 se adquiere un remolcador a vapor, el Caupolicán, buque con casco de madera, para el transporte de las chalupas. El buque 
"llevaba dos chalupas arriba colgadas, encima del casco del barco, en el puente, allí llevaba dos chalupas" y "no remolcaban la ballena por la popa, como quien arrastra un auto, sino al costado, como un ballenero propiamente tal"48. En 1936 el Caupolicán fue reemplazado por el Atlas, buque con casco de hierro, más grande y con más potencia (Hernández, 1998: 40).

En 1944 muere Don Juan Macaya Aravena y en 1946 se adquiere el Juan I (ex Indus 2), el primer buque cazador a vapor que posee la empresa. Este buque provoca un cambio radical pues se dejan de lado las chalupas para la cacería, ya que el Juan I estaba dotado de un poderoso cañón, que además de aumentar la cantidad de capturas, permite la caza de nuevas especies que estaban fuera del rango de acción de las chalupas. Se comienzan a cazar cachalotes, ballenas azules y de aleta bajo un nuevo modelo, el de la caza moderna de ballenas (Tønnesen \& Johnsen 1982). Ese mismo año se cambia el nombre de la empresa a Compañía de Pesca y Comercio Macaya Hermanos, y se empieza a preparar el traslado de la planta ballenera al continente, ya que el aumento de la producción hace insuficiente la infraestructura instalada en la isla. El resto es otra historia (Pastene, 1981; Hernández 1998).

Foto 2: Cuerpo de una ballena sin su capa de grasa en caleta Tumbes, c. 1940

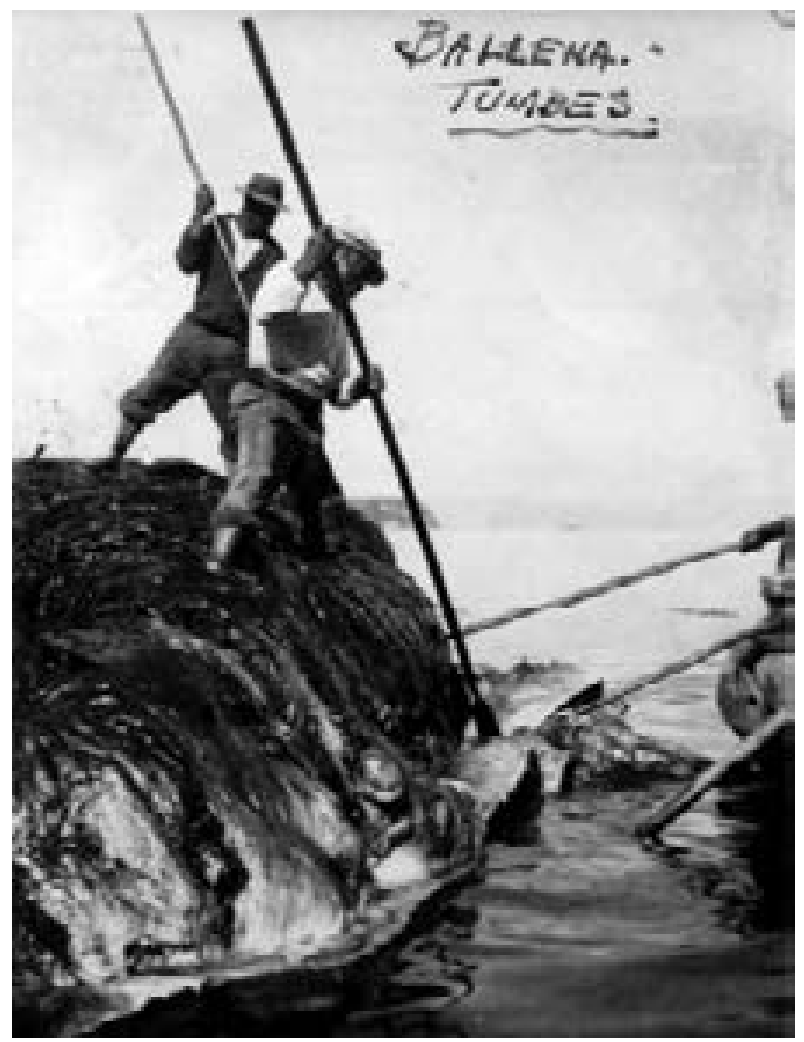

(Foto gentileza de Luis Salvo) 


\section{Clausura}

La caza de ballenas con chalupas y arpón de mano permanece en la memoria de la gente en muchos lugares de la costa centro sur de Chile. Son recuerdos, dispersos por toda la costa del centro sur de Chile, que permiten, al mezclar el pasado con el presente, afirmar que la pesca de ballenas sigue vigente y podemos reconocerla y representarla.

Pedro Aguirre, de Isla Mocha, contaba en 1992 que estuvo "como seis años en eso, en la isla Santa María, trabajaba en la ballena y en la pesca", que la ballena era "algo difícil para pillarla, tiene que ser una suerte, una casualidad, porque la ballena no sube con todo el cuerpo, es un poquito lo que se asoma del agua", que " cuando se divisa la ballena salen los botes y se acercan a la ballena, ahí los trancadores ensartan la ballena, hay que ser harto valiente, porque la ballena de un golpazo de la cola hace pedazos todo lo que pilla y la gente también se ahoga". Agrega que "cuando se ensarta la ballena hay que tratar de que no se vaya a pique, que no se pierda". Por eso, "estando ensartada viene otro bote más, dos o tres botes y ahí está lista la cosa". Más tarde "llega la lancha, la pesca y se la lleva para arriba, para pelarla, como se dice, o sea, para sacarle la gordura". Los pedazos de tocino "son grandes, son gruesos y dan harto, una ballena da como 40 tambores de aceite". Finalmente, "la grasa hay que freírla y ahí sale el aceite" ${ }^{\text {9 }}$.

José Mateo Railaf, de Chaihuín, Valdivia, relataba que:

“(...) mi abuelo tenía una chalupa, él cazaba ballenas, el finado de mi abuelo, Pedro Leal. Él tenía esa chalupa, tenía como nueve metros. Eran cuatro bogadores por lado, un bayonero, un arponero y un lancero.
Andaban como once personas en esa chalupa y cazaban la ballena. Ahí la ponían y ya cuando estaban más o menos muertas, las dejaban con banderín y ahí la iba a buscar el remolcador. El remolcador la traía aquí [a San Carlos de Corral] la ballena"50.

José Gómez, de Chonchi, Chiloé, recordaba que su abuelo:

"Carmelo Gómez Vera, su hermano Delfín Gómez Vera y gente de afuera se dedicaban a cazar ballenas, la cazaban con arpones. Primero se acercaban con botes y arponeaban las ballenas y tenían como 200 metros de lazo para que se vaya al fondo y después flotaba. En ese momento decían que le tiraban como unas lanzas para que se desangre y los botes, que eran 3 o 4, la tiraban hacia fuera en la reventazón de la ola, entonces la misma ola la tiraba a tierra. Cuando la ballena varaba en la playa le sacaban la barba, eso lo aprovechaban (...) Yo no vi cazar ballenas, solo le digo lo que me contaron porque era muy chico en esa época. De las ballenas los viejos de antes aprovechaban muy poco porque no le sacaban la grasa ni la carne, eso lo dejaban para que lo coman los pájaros"51.

Para terminar, me gustaría compartir la mirada nostálgica de Luis Castillo por esa caza "artesanal" de la ballena: "son tan pocos los que sobreviven de ese primitivo y heroico período industrial que se extingue: que de él va quedando solo el recuerdo" (Castillo, 1937: 43).

En 1907 ya había señalado que era preferible una caza costera en pequeña escala, más sustentable" a una caza "de tipo industrial" que requiere el uso de un "vapor ballenero", la caza moderna de ballenas (Castillo, 1907: 158-159). En su opinión, "los cetáceos han sido de tal modo perseguidos, que los pocos sobrevivientes de esta persecución inmoderada, han debido recluirse en una zona que ya no puede seguir disputándole el hombre, sino muy de tarde en tarde": los mares árticos y antárticos (Castillo, 1937: 43). 
Recuerda a los antiguos balleneros chilenos: "en esos tiempos [... cuando] el animal era atrapado con una audacia temeraria realmente inconcebible para una época tan cobarde e incolora como la presente". Todo lo hacían "desde una chalupa tripulada por ocho hombres, sin miedo [...], eran esos otros tiempos, que no se han ido del todo. Tiempos de menos pericia profesional quizás, pero de más cachaza" (Op.cit.: 44).

Recuerda ese tiempo "cuando había que tener mucha pana, bogar rápidamente hacia atrás en cuanto el arpón daba en el blanco, pues, de otro modo, la ballena herida, hundiéndose de cabeza, sacaba fuera del agua su enorme cuerpo, azotándolo sobre el agua en un sentido y en otro, como para demoler lo que encontrase". Después vino la caza moderna, donde la industria ballenera "dígase lo que se diga, [...] es ante todo una industria noruega", característica de esta época "tan cobarde e incolora", donde no queda espacio para héroes. (Ibídem).

El escrito de Castillo indica el fin de la "pesca" de ballenas en las costas de Chile y su remplazo por la caza moderna de ballenas, la que continuará hasta 1983, cuando uno de los nietos de Juan Macaya, Héctor Macaya Silva, capitán del Juan 9, capture la última ballena en las costas chilenas, una ballena de aleta. Su esqueleto se puede observar hoy en los jardines del Departamento de Oceanografía, en la Universidad de Concepción (Pastene \& Quiroz, 2010).

\section{Notas}

${ }^{1}$ Este trabajo se inscribe en el Proyecto FONDECYT Regular № 1140056 (2014-2016) financiado por la Comisión Nacional de Investigación Científica y Tecnológica-CONICYT: "Una etnografía retrospectiva de la caza de ballenas en las costas de Chile durante el siglo XIX".

${ }^{2}$ El Faro del Bío Bío (Concepción), № 12, 7 de enero de 1834.

${ }^{3}$ Podemos leer en la prensa que a comienzos de 1918, "los pescadores de Tumbes, pescaron dos ballenas, una de estas se les fue a pique" El Sur (Concepción), 15 de Abril de 1918.

${ }^{4}$ Escritor, lingüista y militar chileno, estudioso de la geografía, historia, lenguas y terremotos del país, nace en Cauquenes en 1837 y muere en Santiago en 1923.

${ }^{5}$ Diplomático, poeta y Premio Nacional de Literatura en 1958, nacido en Angol en 1877 y fallecido en Santiago en 1968.

${ }^{6}$ En esos años Luis Castillo, biólogo, trabajaba en la Sección de Bosques y Aguas del Ministerio de Industrias y Obras Públicas.

7 Tenemos datos sobre unas instalaciones que en 1838 tenía Don Antonio V. Vergara en la isla Quiriquina para el procesamiento de los productos de la pesca de la ballena. [Solicitud de Antonio V. Vergara al Intendente de Concepción, 12 de septiembre de 1838]. Intendencia de Concepción, 152, f. 235-236v. Archivo Histórico Nacional (Santiago de Chile). De la misma época es una litografía que muestra "un establecimiento de balleneros en la isla Quiriquina" publicado en el Atlas Pittoresque del Voyage au pole sud et dans l'Oceanie sur les corvettes l'Astrolabe et la Zelee, crónica del viaje realizado entre 1837 y 1840 por el explorador francés Jules Sebastian
Cesar Dumont D'Urville.

${ }^{8}$ Informe del Intendente de Concepción en contestación a la Circular del 6 de marzo de 1854. Memoria del Ministerio de Marina. Santiago: Imprenta Nacional, 1854, pp. 51, 54.

9 [Manuscritos censales de Talcahuano]. Archivo Nacional, Fondo Intendencia de Concepción, volumen 421.

${ }^{10}$ Memoria de la Gobernación Marítima de Concepción. Memoria que el Ministerio de Marina presenta al Congreso Nacional, 1864. Santiago: Imprenta Nacional: 144-151.

${ }^{11}$ Memoria del Gobernador Marítimo de Talcahuano, 1 de abril de 1875. Puerto de Talcahuano. Memoria que el Ministerio de Marina presenta al Congreso Nacional. Santiago: Imprenta Nacional, 1876, p. 269-270.

12 La Tarántula (Concepción), 1 de marzo de 1869.

${ }^{13}$ Araya, M. Memoria de la Subdelegación Marítima de Lebu, Lebu, 4 de abril de 1868. La Tarántula (Concepción), 18 de abril de 1868.

${ }^{14}$ Movimiento Marítimo, Puerto de Lebu. La Tarántula (Concepción), 19 de agosto de 1868.

${ }^{15}$ Pozzi, C. Memoria del Gobernador Marítimo de Talcahuano, 1 de abril de 1876. Puerto de Lebu. Memoria que el Ministerio de Marina presenta al Congreso Nacional. Santiago: Imprenta Nacional, 1876, p. 285.

${ }^{16}$ Ramos, S. Jente de mar i embarcaciones menores matriculadas en 1896 i existentes en 31 de diciembre en la Gobernación Marítima de Valdivia. Memoria que el Ministerio de Marina presenta al Congreso Nacional. Santiago: Barcelona, 1897, pp. 838-839. 
${ }^{17}$ Entrevista con Raúl Paviez, Amargos, 15 de noviembre del 2008

${ }^{18}$ La Cruz del Sur (Ancud), 7 de noviembre de 1903.

${ }^{19} \mathrm{La}$ Cruz del Sur (Ancud), 14 de noviembre de 1903.

${ }^{20}$ La Cruz del Sur (Ancud), 5 de diciembre de 1903

${ }^{21}$ El Comercio (Punta Arenas), 7 de abril de 1905.

${ }^{22}$ Esta información les fue proporcionada a los autores por Andrea Soto, una historiadora local.

${ }^{23}$ El Comercio (Valdivia), 27 de julio de 1908.

${ }^{24}$ El Comercio (Valdivia), 4 de noviembre de 1908.

${ }^{25}$ La Cruz del Sur (Ancud), 5 de diciembre de 1903.

${ }^{26} \mathrm{La}$ Cruz del Sur (Ancud), 23 de enero de 1904.

${ }^{27}$ Entrevista a Sixto Venegas, Pumillahue, Chiloé, 2006 (Águila 2006: 31)

${ }^{28}$ Chile Austral (Punta Arenas), 5 de noviembre de 1910.

${ }^{29} \mathrm{El}$ Comercio (Punta Arenas), 7 de abril de 1905.

${ }^{30}$ Información proporcionada por Luisa Oróstica a Antonio Fernández, quién la transcribe en su trabajo. El dato puede referirse tanto a Inglaterra como Estados Unidos.

${ }^{31}$ Denominación genérica usada por uno de los informantes de Fernández. Sin duda se está refiriendo a carabinas norteamericanas.

${ }^{32}$ Bombo lanza es una curiosa castellanización del término inglés bomb lance, cuya traducción más bien sería lanza bomba. El mismo término, bombo-lanza, es recogido en 1905 en Tumbes por Dublé Urrutia (1905a: 4).

${ }^{33}$ Memoria de la Gobernación Marítima de Concepción. Memoria que el Ministerio de Marina presenta al Congreso Nacional, 1864. Santiago: Imprenta Nacional: 144-151.

${ }^{34}$ Memoria del Gobernador Marítimo de Talcahuano, 1 de abril de 1875. Puerto de Talcahuano. Memoria que el Ministerio de Marina presenta al Congreso Naciona1. Santiago: Imprenta Nacional, 1876, p. 269-270.

${ }^{35}$ Un galón es igual a 3,78 litros; Una libra es igual a 0,45 kilógramos.

${ }^{36}$ Memoria de la Gobernación Marítima de Concepción. Memoria

\section{Referencias Bibliográficas}

Águila, V. (2006). Para una historia oral de la relación entre cetáceos y comunidades costeras: El caso de la bahía de Pumillahue (Ancud, Chiloé). (Informe de Práctica Profesional para optar al Título de Licenciatura en Antropología). Universidad Austral de Chile.

Andrade, M. A. \& Pacheco, R. (2012). Memorias de la Mar. Valdivia: Imprenta América.

Barkam Huxley, M. (1998). "Las pequeñas embarcaciones costeras vascas en el siglo XVI: notas de investigación y documentos de archivo sobre el 'galeón', la 'chalupa' y la 'pinaza'”. Itsas-Memoria, № 2.

Bezerra, A. S. (2015). "Arquivo e memória oral na produção de uma 'etnografia retrospectiva”'. ANTROPOlógicas, № 13 .

Cañas Pinochet, A. (1902). "La Isla de la Mocha". Actas de la Sociedad Científica de Chile, № XII. que el Ministerio de Marina presenta al Congreso Nacional, 1864. Santiago: Imprenta Nacional, p. 150.

${ }^{37}$ Valparaíso en la Exposición Nacional de 1884. Valparaíso: Imprenta del Nuevo Mercurio, 1884, pp. 111-112.

${ }^{38}$ [Memoria del Ministerio de Marina, 1919]. Archivo Nacional, Fondo Ministerio de Marina, Volumen 2292, f. 44.

${ }^{39}$ Valparaíso en la Exposición Nacional de 1884. Valparaíso: Imprenta del Nuevo Mercurio, 1884, pp. 111-112.

${ }^{40}$ Sus diez hijos varones fueron Juan Segundo, Anselmo, Ramón, Abel, Francisco, Leovigildo, Enrique, Fernando, Roberto y Neftalí. Sus dos hijas eran Digna y Marta.

${ }^{41}$ Anselmo usa el término "abuelo" para nombrar a su padre, Juan Macaya, pues así era conocido por toda su familia.

${ }^{42}$ Entrevista a Anselmo Macaya, Chome, 1971 (Rojas, 1971: 31)

${ }^{43}$ Entrevista realizada a Osvaldo Ramírez, Chome, 2010 (Espinoza, 2011: 64).

${ }^{44}$ Entrevista realizada a Carlos Macaya, Chome, 2010 (Espinoza, 2011: 65).

${ }^{45}$ Entrevista realizada por Gastón Carreño a Flor Monsalve, Chome, 2002 (Espinoza, 2011: 71).

${ }^{46}$ Entrevista realizada a Alfredo Herrera, Isla Mocha, 1992 (Quiroz \& Zumaeta, 1997: 24).

${ }^{47}$ Entrevista realizada a Juan Hernández, Talcahuano, 2010 (Espinoza, 2011: 70)

${ }^{48}$ Entrevista realizada por Miguel Chapanoff a Waldo Soto, Talcahuano, 2013.

${ }^{49}$ Entrevista a Pedro Aguirre, Isla Mocha, 1992 (Quiroz \& Zumaeta 1997: 25).

${ }^{50}$ Entrevista a José Mateo Railaf, Chaihuín, 2010 (Andrade \& Pacheco, 2012: 24).

${ }^{51}$ Entrevista a José del Carmen Gómez Álvarez, Chonchi, 2008 (Montiel, 2010: 289-290).

Carreño, G. \& Espinoza, A. (2012). "El arpón se queda en la familia: la Ballenera Macaya en el golfo de Arauco". En Adomili, G., Carreño, G., D’Ambrosio, L. \& Miller, F. (eds.), Povos e coletivos pesqueiros. Estudos etnográficos e perspectivas antropológicas sobre o viver o trabalhar. Rio Grande: Editora da FURG (Universidade Federal do Rio Grande).

Cartes, A. (2009). Los cazadores de Mocha Dick. Santiago: Pehuén.

Castillo, L. (1937). "En torno a la industria ballenera". Acción Social, № 65 .

(1907). "La reglamentación de la caza de ballenas". Anales Agronómicos, Vol. II, № 1-2. (1906). "La caza de la ballena en la Isla Santa María". 
Boletín de la Sociedad de Fomento Fabril, № 8 .

Chambeaux, J., Michel, F. \& Retamales, A. (2009). Escafandras bajo el mar. Santiago: Cuarto Propio.

Clark, A. H. (1887). "The Whale Fishery”. En Goode, G. B. (ed.). The Fisheries and Fishery Industries of the United States. Washington: Government Printing Office.

Driessen, H. G. G. M. (2013). "Suspense in Retrospective Ethnography”. En Pelkmans, M. E. (ed.). Ethnographies of Doubt: Faith and Uncertainty in Contemporary Society. Londres: I. B. Tauris.

Dublé Urrutia, D. (1905a). "Tumbes (IV). La pesca de la ballena. José Olivares i las ballenas". El Sur, 5 de febrero. Concepción.

(1905b). "Tumbes (V). La caza de la ballena". El Sur, 7 de febrero. Concepción.

Espinoza, A. (2011). El camino de la ballena: de Santa María a Chome, de Chome al fondo del mar. (Tesis para optar al Grado de Licenciado en Antropología y al Título de Antropólogo Social). Universidad Academia de Humanismo Cristiano, Chile.

Fernández, A. (1964). La caleta y su gente: Tumbes (estudio etnográfico). (Memoria de prueba para optar al Título de Profesor de Estado). Universidad de Concepción, Chile.

Gonçalvez, R. de S. (2009). "Sociabilidades urbanas: cronistas e ranchos carnavalescos no Rio de Janeiro". En Gonçalves, J. R. S. \& Cavalcanti, M. L. V. de C. As festas e os dias: ritos e sociabilidades festivas. Río de Janeiro: Contracapa.

(2008). A dança nobre no espetáculo popular. A tradição como aprendizado e experiencia. (Tesis para obtener el título de Doctor en Ciencias Humanas-Antropologia Cultural). Universidade Federal do Rio de Janeiro, Brasil.

(2007). Os ranchos pedem passagem. Río de Janeiro:

Secretaria Municipal das Culturas.

Hernández, J. (1998). Donde viven las ballenas. Actividades balleneras en Isla Santa María y Chome del pionero Juan Macaya Aravena. Concepción: Aníbal Pinto.

Lennartsson, R. (2011). “Notes on 'Not Being There'. Ethnographic Excursions in Eighteenth-Century Stockholm". Ethnologia Europea/ Journal of European Ethnology, Vol. 41, № 1.

Martinic, M. (2004). "Antecedentes históricos sobre la caza de cetáceos en Chile”. Boletín Antártico Chileno, Vol. 23, № 1.

Montiel, F. (2010). Chiloé, historias de viajeros. Castro: Masterprint.

Olmsted, F.A. (1841). Incidents of a Whaling Voyage. Nueva York: D. Appleton \& Co.

Pastene, L. (1982). Análisis de las capturas de ballenas efectuadas por la industria ballenera nacional en el sector del Pacífico Sur Occidental correspondientes a Chile y consideraciones del estado actual de dicha industria y su desarrollo histórico. (Tesis para optar al Título de Biólogo Marino). Concepción: Universidad de Concepción.
Pastene, L.A. \& Quiroz, D. (2010). "Outline of the History of Whaling in Chile". En International Center for Folk Culture Studies (ed.). Human Culture from the Perspective of Traditional Maritime Communities, International Symposium Report No. 1. Kanagawa: Kanagawa Shimbun Press.

Pearson, M. (1983). "The Technology of Whaling in Australian Waters in the 19th Century". Australian Historical Archaeology, № 1.

Pereira Salas, E. (1971). Los primeros contactos entre Chile y Ios Estados Unidos, 1778-1809. Santiago: Andrés Bello.

Pizarro, A. (1994). Lebu, de la Leufumapu a su centenario 15401962 (2ª edición). Santiago: Ñielol.

Quiroz, D. (2015a) "Balleneros en la niebla: una mirada paraetnográfica de la caza de ballenas en Chile". Chungara, Vol. 47, № 2 . (2015b). Cazadores clásicos de ballenas en las costas de Chile (1819-1921). Santiago: Centro de Documentación de Bienes Patrimoniales, Dirección de Bibliotecas, Archivos y Museos. (2012). Cazadores tradicionales de ballenas en las costas de Chile (1850-1950). Santiago: Centro de Documentación de Bienes Patrimoniales, Dirección de Bibliotecas, Archivos y Museos.

(2010). "Una breve crónica de la cacería de ballenas en Valdivia (1906-1936)". Revista Austral de Ciencias Sociales, Vol. 19.

Quiroz, D. \& Zumaeta, H. (1997). "Ecología, historia y cultura en isla Mocha, provincia de Arauco". En Quiroz, D. \& Sánchez, M. (eds.). La isla de las palabras rotas. Santiago: Centro de Investigaciones Diego Barros Arana.

Reeves, R. R. \& Smith, T. D. (2006). "A Taxonomy of World Whaling: Operations, Eras, and Data Sources". En Estes, J. A., DeMaster, D. P., Doak, D. F., Williams, T. M. \& Brownell R. L. Jr. (eds.). Whales, Whaling and Ecosystems. Berkeley: University of California Press.

Rojas, D. (1971). "Ballena a la vista. Entrevista a Anselmo Macaya Medina". Ramona, № 2.

Salvo, L. (2000). Historia de la industria pesquera en la Región del Bío Bío. Santiago: LOM.

Sandoval, A. (1978). "Talcahuano y los últimos balleneros a vela". Revista de Marina, Vol. 89, № 3.

Thomas, K. (2009). The Ends of Life: Roads to Fulfillment in Early Modern England. Oxford: Oxford University Press.

Tilly, Ch. (1978). "Anthropology, History and the Annales". Review, Vol. I, № 3-4.

Tønnesen, J. N. \& Johnsen, A. O. (1982). The History of Modern Whaling. Berkeley y Los Angeles: University of California Press. 